\title{
The Language of Argumentation: Book Review
}

\author{
Nico Irawan, Tri Febrianti Valentina \\ Rajamangala University of Technology Krungthep
}

Correspondence concerning this article should be addressed to Nico Irawan, Khwaeng Thung Maha Mek, Khet Sathon, Krung Thep Maha Nakhon 10120,Thailand.E-mail: nico.i@mail.rmutk.ac.th

\section{Boogaart, R., Jansen, H., van Leeuwen, M. (Eds.). (2021). The language of argumentation. Springer. ISSN: $1566-7650$}

\begin{abstract}
The Language of Argumentation by Ronny Boogaart, Henrike Jansen, \& Maarten van Leeuwen (Eds). Switzerland: Springer Nature Switzerland AG. 2021 aims to provide important theoretical insights to the international community of argumentation theorists by informing them of recent developments in the field. Some aspects of argumentative texts may emerge as a result of the argumentation process. This book covers different types of argumentative procedures and enthymematic argumentation, argumentation structures, argumentation schemes, and fallacies. Specifically, contributions are solicited from authors trained in informal or formal logic, modern or classical rhetoric, and discourse analysis or speech communication.
\end{abstract}

One of the central aims of the rhetorical tradition has been the analysis of language's communicative capabilities to present arguments with the maximum effect over time. The Language of Argumentation brings various approaches to gain a more global perspective on current research in this domain and facilitate discussion within and across disciplcines. This book is divided into three sections. In Chapters of Part I, leading researchers in their respective fields reflect on broad theoretical and methodological issues. Part II chapters begin with a specific argumentative move and present the various ways in which it manifests in discourse, and Part III chapters start with one particular rhetorical figure or linguistic construction and are focus on its argumentative function and strategic potential. The introduction to the chapters provides an overview of the book, links the chapters together, relates them to developments in argumentation theory and linguistics, and describes their significance within the issue of the book: argumentation is fundamentally linked to language.

In Part I Theoretical and Methodological Considerations, in the chapter "Characterizing Argumentative Style: The Case of KLM and the Destructed Squirrels," Frans van Eemeren investigates the concept of "argumentative style" within the framework of pragma-dialectical argumentation theory. Among theories of argumentation, the pragma-dialectical approach has always included a language use perspective in the study of argumentative discourse. In the chapter "Argumentation in Evolution: On the Relationship Between Dyadic and Public Communication," Arie Verhagen contributes to the debate about the origin and function of argumentative language by critically examining two views on the evolution of
Argumentation Library

Ronny Boogaart

Henrike Jansen

Maarten van Leeuwen Editors

\section{The Language of Argumentation}


argumentation. Verhagen demonstrates that there are two significant differences between these approaches: one regarding the evolutionary stage at which argumentation is assumed to have emerged, and the other regarding the importance of dyadic communication (social interaction) or public communication (communitywide decision making). Blair's argumentation theories address a particular topic in the domain of language and argumentation, namely language used in argumentation; in the chapter "Technical Terminology and Argument Analysis and Appraisal," Anthony Blair addresses the question of whether laymen arguers need a technical vocabulary to understand (i.e., interpret and assess) argumentation. Finally, in the chapter "Analyzing Rhetorical Style: Toward Better Methods," Jeanne Fahnestock, whose works on style and persuasion are considered landmarks in the field of argumentation language, notes that linguistic analyses of a text typically produce so much data that analysts can easily select those data that suit their ideological agenda.

Chapters in Part II focus on relation between argumentation and language. In the chapter "Those are your words, not mine!" Defense Strategies for Denying Speaker Commitment" in contrast to traditional studies of commitment in linguistics researchers seek to demonstrate that both denials of responsibility to an implicature and denial of commitment to literal meaning exist in people. In the chapter "Uses of Linguistic Argumentation in the Justification of Legal Decisions," Eveline Feteris, Harm Kloosterhuis, and José Plug examine linguistic arguments based on the (alleged) semantics of the wording in a statutory norm. The fact that linguistic arguments can be used in four different ways and for four other purposes helps explain why the use of linguistic arguments in legal decisions is as divisive as it is lauded as a means of determining the principles of the Rule of Law. Andrea Rocci in the chapter "Diagramming Counterarguments: At the Interface Between Discourse Structure and Argumentation Structure" is more focused on discourse structure, while Assimakis Tseronis in "How Face Threatening Are Disagreement Moves? A proposal for an integration of insights from politeness theory into argumentation theory" is more focused on argumentation structure. Tseronis classifies the moves in question using the formal distinction between declarative and interrogative utterances.

Part III From Language to Argumentation focuses on "flipping the argument/language connection" by using a specific linguistic form as the starting point rather than an argumentative function. In the chapter "The Strategic Use of Metaphor in Argumentation," Roosmaryn Pilgram and Lotte van Poppel investigate the strategic functions of metaphor in argumentative discourse by combining insights from the extended pragma-dialectical theory of argumentation with insights from cognitive linguistics' three-dimensional (3D) metaphor model (Steen, 2008). In the chapter "The Maxims of Common Sense: Strategic Manoeuvring with Figurative Analogies," Bart Garssen argues that figurative analogies should be viewed as arguments based on a causal or symptomatic argument scheme rather than analogy argumentation. A figurative analogy is an example of indirect language; the argument must be reconstructed to be evaluated. This raises the question of why arguers would use such a presentational device when a more direct presentation is also possible. In response to this question, Garssen discusses three strategic functions of figurative analogies: transferring the "phoros" (source) connotations to the "theme" (target), preventing an antagonist from raising critical questions, and introducing controversial propositions as starting points.

Bregje Holleman and Henk Pander Maat report on two such experiments in the chapter "Empty is Emptied: How Frame Choice Affects Previous State Inferences," testing the effect of the attribute framing device, i.e., the choice of one value of a two-sided variable as in "the glass is half full/half empty." Ineke Sluiter discusses the phenomenon of "anchoring" in the chapter "Old is the New New: The Rhetoric of Anchoring Innovation," beginning with how this concept is used in linguistics to capture the semantics and pragmatics of grammatical categories such as tenses and pronouns. Egbert Fortuin describes the argumentative function of one Russian expression in the chapter "Drawing Attention to Information in Russian Argumentation: The Function of the Performative Expression važno podc "erknut' ("It Is Important to Emphasize"). Henrike Jansen and Francisca Snoeck Henkemans present a study of the argumentative and rhetorical function of the English expression "not for nothing" in the chapter "Strategic Manoeuvring with the Expression «Not for Nothing." They describe the various types of standpoints and the various types of argument schemes that can be used with them. Furthermore, they show that the strategic value of "not for nothing" stems from the implication that adequate support has been provided when, in fact, this support has been left implicit.

Finally, in the chapter "Everybody Knows That There Is Something Odd About Ad Populum Arguments," Steve Oswald and Thierry Herman describe the argumentative function and rhetorical potential of the expression "everyone/everybody knows P" from a post-Gricean (relevance-theoretic) perspective. They place a particular 
emphasis on two issues with regard to construction: understanding "everyone/everybody" as a universal quantifier and finding different types of propositions stored in the variable P. These academics contend that, while linguistic issues reveal the construction's rhetorical potential as well as which uses are illicit, those issues also serve as instructional devices. Through the examination of a single construct, they obtain greater insight into appeals to commonly held beliefs, illustrating the value of a linguistic-pragmatic approach to inquiry on the topic of argumentation.

In summary, three parts of this book examined various general observations about argumentation and language and the interconnectivity of those phenomena to support Fahnestock's theory, demonstrating how general observations such as these are followed by the approach and lead to the discovery of more narrowly defined devices, such as figures of speech. All the material begins with a well-formulated and somewhat preliminary argument and then followed by a review all the other types of argumentations in the book. One way to illustrate the concept is to say that in most arguments, people start with a particular argumentation function (a claim, an explanation, etc.) rather than a specific linguistic form (a pronoun, a definite article, etc.).

This book is dedicated to Ton van Haaften, who recently retired from Leiden University as a Full Professor of Dutch Discourse Studies. Van Haaften's research has concentrated on the interface between language use and argumentation, particularly in the institutional domains of law and politics, where the linguistic-stylistic approach is explicitly integrated into the pragma-dialectical theory of strategic maneuvering. Van Haaften worked tirelessly to develop a coherent research program for the Leiden Dutch Discourse Studies group by focusing the group's research on the intersection of linguistics and argumentation and encouraging members to collaborate on this topic specifically. His academic work demonstrates how to connect the study of language use and argumentation by synthesizing and integrating insights from both academic disciplines.

This book's insights may relate to argumentation itself, but they may also apply to aspects of argumentative texts that result from the process of argumentation. Thus, there is a variable associated with the language of argumentation in this book. This book covers numerous topics, such as the features of enthymematic argumentation, argumentation structures, argumentation schemes, and fallacies, while additionally providing examples of enthymematic, hybrid, and forceful approaches. This book will be of great interest to people in learning language argumentation regarding knowledge of appeals to common wisdom, further illustrating the importance of using a linguistic point of departure in studying argumentation and the significance of these interconnections, as demonstrated in this excellent book for all readers.

This is an engaging and practical book for practitioners, academics, researchers, and guidance and counseling students. The explanation is concise and written in an accessible technical and academic English. The proposed framework for argumentative language is the result of extensive argumentative literature, practice, model, and rigorous research conducted by several scholars and edited by Ronny Boogaart, Henrike Jansen, and Maarten van Leeuwen (Eds). Additionally, the proposed framework has been implemented on guidance and argumentative theory and activities in several demonstrations and implementations of various types of argumentation, most notably in language. As a result, it provides a comprehensive, concrete, and applicable framework. Perhaps, as this is a practical guidebook, each definition used in this book is not discussed in detail. Finally, it undoubtedly serves as a straightforward guide for the reader to understand what language of argumentation can imply and how it can be applied in numerous facets of life, to appreciate the significance of both general language of argumentation evaluation and culturally based implementation of the theory of argumentation, which are rarely the focus of resources. We believe that this book can serve as a valuable resource for all readers and scholars interested in comprehending the language of argumentation in theory and practice, mainly to improve the field's skills and competencies.

\section{References}

Steen, G. (2008). The paradox of metaphor: Why we need a three-dimensional model of metaphor. Metaphor and Symbol, 23(4), 213-241. https://doi.org/10.1080/10926480802426753 